\title{
A Quantitative PCR System for Measuring Sclerotinia sclerotiorum in Canola (Brassica napus)
}

B. R. Ziesman, Department of Agricultural, Food and Nutritional Science, University of Alberta, Edmonton, AB, T6G 2P5, Canada; T. K. Turkington, Lacombe Research Centre, Agriculture and Agri-Food Canada, Lacombe, AB, T4L 1W1, Canada; and U. Basu and S. E. Strelkov, Department of Agricultural, Food and Nutritional Science, University of Alberta

\begin{abstract}
Ziesman, B. R., Turkington, T. K., Basu, U., and Strelkov, S. E. 2016. A quantitative PCR system for measuring Sclerotinia sclerotiorum in canola (Brassica napus). Plant Dis. 100:984-990.

Sclerotinia stem rot, caused by Sclerotinia sclerotiorum, is an economically important disease of canola (Brassica napus) commonly managed by routine application of fungicides. Petal infestation has been demonstrated to be an important stage of the disease cycle in canola and has been the focus of previously developed Sclerotinia stem rot risk assessment methods. Quantitative polymerase chain reaction (qPCR) analysis can provide a more rapid and accurate assessment of petal infestation levels. Primers and a hydrolysis probe were designed to amplify a 70-bp region of an S. sclerotiorum-specific gene, SS1G_00263. A hydrolysis

probe-based qPCR assay was developed that had a detection limit of $8.0 \times 10^{-4} \mathrm{ng}$ of $S$. sclerotiorum DNA and only amplified $S$. sclerotiorum DNA. Evaluation of petals collected at five sampling points in each of 10 commercial canola fields on each of two sampling dates (corresponding to 20 to $30 \%$ bloom and 40 to $50 \%$ bloom) revealed S. sclerotiorum DNA infestation levels of 0 to $3.3 \times 10^{-1} \mathrm{ng} / \mathrm{petal}$. This qPCR assay can be used to reliably quantify petal infestation and, with further research, has the potential to serve as the basis for a Sclerotinia stem rot risk assessment tool or as a means to study Sclerotinia stem rot epidemiology.
\end{abstract}

Sclerotinia stem rot, caused by the ascomycete fungus Sclerotinia sclerotiorum (Lib.) de Bary, is an economically important disease of canola (Brassica napus L.) (Purdy 1979; Willetts and Wong 1980). Yield losses can be as high as $50 \%$, with a yield reduction of $0.5 \%$ estimated for every $1 \%$ increase in disease incidence (del Río et al. 2007). The fungus overwinters as sclerotia, which can germinate carpogenically in the spring to produce apothecia (Abawi and Grogan 1979; Bardin and Huang 2001; Willetts and Wong 1980). Mature apothecia will forcibly release windborne ascospores (Abawi and Grogan 1979). The ascospores come into contact with canola petals onto which they adhere; then, the ascospores germinate and penetrate the petal tissue to initiate infection (Jamaux et al. 1995; Purdy 1979). Petal infestation has been shown to be an important stage in the Sclerotinia stem rot disease cycle (Jamaux et al. 1995; Morrall and Dueck 1982). After senescence, the infected petals fall into the crop canopy and the fungus grows from these petals, infecting the leaf and stem tissues. The first visible symptoms of disease consist of browning on and around the cast petals. As the fungal infection spreads to the stems, the characteristic symptoms of Sclerotinia stem rot appear, including bleached whitish-gray lesions where the infected host stem tissues are very brittle, shredding and shattering when dry (Bolton et al. 2006; Jamaux et al. 1995; Young and Werner 2012). Once the infection is well established, hard black survival structures known as sclerotia are produced by the fungus inside the stem. The sclerotia can be dislodged during harvest and serve as inoculum in subsequent years.

The development of Sclerotinia stem rot of canola is influenced by environmental conditions; in particular, temperature and moisture. For carpogenic germination of the sclerotia to occur, continuous soil moisture, near saturation, for about 10 days and moderate temperatures are required (Abawi and Grogan 1979; Schwartz and Steadman 1978; Wu and Subbarao 2008). Ascospore release has been found to be highest at 20 to $25^{\circ} \mathrm{C}$, with the ascospores being able to survive for

Corresponding author: S. E. Strelkov; E-mail: stephen.strelkov@ualberta.ca Accepted for publication 13 December 2015.

http://dx.doi.org/10.1094/PDIS-05-15-0605-RE

(C) 2016 The American Phytopathological Society up to 2 weeks in the environment (Abawi and Grogan 1979; Clarkson et al. 2003). Infection of stem and leaf tissue by S. sclerotiorum is favored in the presence of free water and moderate temperatures ( 15 to $\left.25^{\circ} \mathrm{C}\right)$ whereas, at extreme temperatures $\left(<4^{\circ} \mathrm{C}\right.$ and $\left.>30^{\circ} \mathrm{C}\right)$, fungal growth is restricted (Bolton et al. 2006; Willetts and Wong 1980).

The wide host range of $S$. sclerotiorum, along with the influence of temperature and moisture conditions on apothecial development and subsequent plant infection, have limited the effectiveness of cultural stem rot management practices. Crop rotations that include 4 years away from a susceptible host were found to be ineffective for Sclerotinia stem rot management, as a consequence of the survival of viable sclerotia in the soil and the introduction of ascospores from external sources (Morrall and Dueck 1982). Sclerotinia stem rot-tolerant canola cultivars have become available recently in Canada but, when the risk of disease is high, even these cultivars can suffer damage and require fungicide application (Canola Council of Canada 2014; Pratt 2012). As a consequence, the application of fungicides is the primary management tool for Sclerotinia stem rot of canola. To be effective, fungicides need to be applied during the key stage for infection (i.e., at flowering and before the appearance of symptoms in the crop). Therefore, the application of fungicide often must be made without any objective indication of disease risk (del Río et al. 2007; Koch et al. 2007; Turkington et al. 2011).

In an effort to predict the likelihood of Sclerotinia stem rot development in a given canola crop, a petal test was developed whereby field-collected petals were plated onto potato dextrose agar (PDA) and incubated for 3 to 5 days (Morrall and Thomson 1991). The cultured petals were then examined for growth and the resulting colonies were identified. The proportion of petals that yielded colonies of S. sclerotiorum was taken as the percent petal infestation. Risk assessments were provided based on the statistical relationship between petal infestation and final Sclerotinia stem rot development in the field, and were calculated based on percent petal infestation (Gugel and Morrall 1986; Turkington et al. 1991). The percent petal infestation was used to identify the Sclerotinia stem rot risk level as low, moderate, or high based on the relationship between this parameter and disease incidence (Turkington and Morrall 1993; Turkington et al. 1991). The 3- to 5-day incubation period that is required for accurate estimates of petal infestation represents a potential disadvantage of this system, because timely spray decisions need to be made during a fairly narrow window of crop development (McLaren 
et al. 2004; Turkington et al. 1991). A molecular approach such as quantitative polymerase chain reaction (qPCR)-based analysis may represent an alternative method to determine petal infestation levels without the time delay associated with incubation of the petals. Moreover, PCR-based methods can lower the risk of human error associated with the misidentification of the fungal cultures growing out of the infested petals.

In recent years, many qPCR-based methodologies have been developed to detect and quantify plant pathogens, including S. sclerotiorum (Almquist and Wallenhammar 2015; Freeman et al. 2002; Parker et al. 2014; Rogers et al. 2009; Yin et al. 2009). Freeman et al. (2002) established a touchdown PCR assay to quantify $S$. sclerotiorum DNA in airborne ascospores of the pathogen and inoculated canola petals. The primers SSFWD and SSREV amplified a 278-bp fragment of ribosomal DNA and were found to be specific to $S$. sclerotiorum, even in the presence of a 40 fold excess of Botrytis cinerea DNA. However, this primer set was unable to distinguish between the DNA of $S$. sclerotiorum and that of close relatives such as $S$. minor and $S$. trifoliorum. Nonetheless, Almquist and Wallenhammar (2015) were able to use the primers of Freeman et al. (2002) to develop a hydrolysis probe-based qPCR assay for detection of $S$. sclerotiorum DNA in air samples and infected leaves and petals of oilseed rape (Brassica napus) in central Sweden. Rogers et al. (2008) described an intercalating dye-based qPCR assay to quantify airborne ascospores of S. sclerotiorum around oilseed rape crops near Rothamsted, United Kingdom, using primers designed to amplify a region of the mitochondrial small subunit (MtSSu) ribosomal RNA (rRNA) and open reading frame 1 of the fungus. This assay could detect $S$. sclerotiorum DNA with a high level of sensitivity and specificity, even in the presence of DNA from the closely related fungus Botrytis cinerea, except at $5 \times 10^{-5} \mathrm{ng}$ of DNA, where the sensitivity of the quantification of $S$. sclerotiorum DNA was reduced (Rogers et al. 2009). Parker et al. (2014) developed another intercalating dye-based qPCR assay for the quantification of airborne ascospores of S. sclerotiorum, as part of a model for forecasting Sclerotinia rot of carrot (Daucus carota subsp. sativus). The assay targeted the group I intron of the MtSSu rRNA, and could detect $93 \%$ of the S. sclerotiorum isolates tested, although the quantification cycle $\left(\mathrm{C}_{\mathrm{q}}\right)$ values varied for different isolates. Although this assay may be useful for the detection of airborne ascospores of $S$. sclerotiorum on a regional scale, $7 \%$ of the isolates tested could not be detected, indicating the potential for false negatives. The variation in $\mathrm{C}_{\mathrm{q}}$ values observed for different isolates also is a cause for concern, because it is indicative of differences in the ability to quantify isolates. This likely would result in inconsistencies in the quantification of the same amount of inoculum, depending upon which isolate is tested, particularly if the standard curve is based on another isolate. Moreover, on carrot, there is no initial petal infestation stage, with infection first occurring on senesced leaves in a closed canopy, and the additional risk of postharvest infection (Kora et al. 2005).

Most relevant to the current study, Yin et al. (2009) developed an intercalating dye-based qPCR assay for the quantification of S. sclerotiorum DNA on canola petals in China. The primers SsF and SsR targeted a region amplified by the microsatellite primer M13 (Ma et al. 2003). The authors reported that this assay was very specific to $S$. sclerotiorum and could quantify as little as $5.0 \times 10^{-4} \mathrm{ng}$ of DNA of the fungus. The specificity of the primers $\mathrm{SsF}$ and $\mathrm{SsR}$, however, was not validated by testing with DNA of pure cultures of other Sclerotinia spp. such as $S$. minor or $S$. trifoliorum. Analysis of infected canola petals resulted in quantifications of $S$. sclerotiorum DNA ranging from $2.5 \times 10^{-2}$ to $1.1 \times 10^{-1}$ $\mathrm{ng} / \mathrm{mg}$ of canola petal tissue. This assay may have value as the basis for a risk assessment tool in canola production systems in Canada. Nevertheless, because of evidence of a high level of genetic variation in the S. sclerotiorum population (Carpenter et al. 1999; Sirjusingh and Kohn 2001), specificity testing would be needed to ensure that Canadian isolates of the fungus can be detected with no false positives. In addition, it would be important to ensure that there is no difference in the detection and quantification of different $S$. sclerotiorum isolates.

The objective of the current study was to develop an S. sclerotiorumspecific qPCR assay for the quantification of Canadian isolates of S. sclerotiorum on canola petals using a hydrolysis probe. Development of this assay was focused on petals rather than airborne inoculum because of the importance of petal infestation in the disease cycle of Sclerotinia stem rot of canola. In addition, estimates of petal infestation may provide a better field-specific indication of disease risk, while detection of airborne inoculum would be best for regional risk assessments. The qPCR assay described in this study also was compared with the qPCR assay developed by Yin et al. (2009), in order to evaluate the potential utility of each method for quantifying $S$. sclerotiorum DNA on canola petals.

\section{Materials and Methods}

DNA isolation from fungal mycelium. Pure fungal cultures of S. sclerotiorum and the other fungal species used for specificity testing (Table 1) were grown on Difco potato dextrose broth (Dickinson and Company, Sparks, MD) that was amended with ampicillin at 25 ppm (Life Technologies, Carlsbad, CA) and streptomycin (SigmaAldrich, St, Louis) in 200-ml Erlenmeyer flasks. The cultures were grown at room temperature (approximately 20 to $24^{\circ} \mathrm{C}$ ) under natural light provided by a north-facing window with gentle agitation for approximately 7 days, until a large mass of mycelium had formed. The supernatant was decanted and the mycelium washed with sterile water, frozen at $-80^{\circ} \mathrm{C}$, and lyophilized in a freeze-drier. Approximately $20 \mathrm{mg}$ of lyophilized tissue was homogenized to a powder in a 1.5-ml microcentrifuge tube with a hand-held plastic pestle, and the DNA was isolated with a Wizard Genomic DNA purification kit (Promega Corp., Madison, WI), as per the manufacturer's instructions but with the addition of a phenol/chloroform/isoamyl alcohol (25:24:1, $\mathrm{vol} / \mathrm{vol} / \mathrm{vol}$ ) purification step. Briefly, following the protein precipitation step, three phenol/chloroform/isoamyl alcohol extractions were performed. In each extraction, $600 \mu \mathrm{l}$ of phenol/chloroform/isoamyl alcohol (25:24:1, vol/vol/vol) was added and the solution mixed and centrifuged. The DNA was quantified with a NanoDrop 2000c spectrophotometer (Thermo Scientific, Waltham, MA), and the $260 / 280 \mathrm{~nm}$ and $260 / 230 \mathrm{~nm}$ absorbance ratios were calculated as an indication of DNA quality prior to qPCR analysis.

DNA isolation from field-collected canola petals. To validate the qPCR assay, canola petals were collected from 10 commercial fields in the Edmonton, AB, Canada region in 2012. These 10 fields were farmed by three different farmers and were known to have a history of Sclerotinia stem rot. The fields were sampled once at 20 to $30 \%$ bloom and again at 40 to $50 \%$ bloom, as determined by visual assessment (Harper and Berkenkamp 1975). These levels of flowering correspond to growth stages 62 to 63 and 64 to 65 , respectively, on the BBCH scale (Weber and Bleiholder 1990; Lancashire et al. 1991). Sampling dates varied slightly in each field depending on crop stage but, in general, sampling at 20 to $30 \%$ bloom was carried out in the first week of July, followed by sampling at 40 to $50 \%$ bloom 3 to 4 days later. The incidence of Sclerotinia stem rot also was assessed at the end of the growing season for future reference. Petals were collected at each of five sampling sites within each field. The sampling sites were located $100 \mathrm{~m}$ from the edge of each field and were situated $50 \mathrm{~m}$ apart along a fungicide-free check strip. At each sampling site, the top 10 to $20 \mathrm{~cm}$ of the inflorescences from each of 20 plants were collected at random, placed in a plastic bag, and stored in a cooler on ice for transport back to the laboratory. At minimum, 80 flowers were selected randomly from the sampled inflorescences and stored in an ultralow-temperature freezer $\left(-80^{\circ} \mathrm{C}\right)$ until further processing.

DNA was isolated according to the protocol of Liang et al. (2013) from a randomly chosen subsample of 20 petals from each sampling site. Petal samples were homogenized with a TissueLyser II (Qiagen, Toronto) and a single 5-mm stainless steel bead in a 2-ml locking tube. The TissueLyser II adapters and petal samples were frozen at $-80^{\circ} \mathrm{C}$ prior to homogenization to prevent damage to the DNA. Prior to elution, the DNA pellets were dried in a Vacufuge Plus (Eppendorf, Mississauga, $\mathrm{ON}$, Canada) for $7 \mathrm{~min}$ at $45^{\circ} \mathrm{C}$. The extracted DNA was eluted with $30 \mu \mathrm{l}$ of nuclease-free water (Life Technologies) and quantified with a NanoDrop 2000c spectrophotometer (Thermo Scientific) as above.

Development of $\boldsymbol{S}$. sclerotiorum-specific primers. Forward and reverse primers and a hydrolysis probe were designed using Primer 3 Express (Applied Biosystems, Carlsbad, CA) based on the 468-bp 
sequence of a single-copy gene (SS1G_00263) encoding the hypothetical secreted protein ssv263 (Liang et al. 2013) from S. sclerotiorum (GenBank accession number XM_001598127). This gene is highly specific to $S$. sclerotiorum and orthologous to protein-encoding gene BC1G_00896 (GenBank accession number XM_001560818) from B. cinerea (Liang et al. 2013; Shah et al. 2009). The forward (SSBZF) and reverse (SSBZR) primers were designed to amplify a 70-bp product in a region of SS1G_00263 that exhibits the greatest difference with the $B$. cinerea ortholog. The hydrolysis probe (SSBZP) was labeled with a nonfluorescent quencher-mini groove binder (NFQMGB) on the $3^{\prime}$ end and with the reporter dye 6-carboxyfluorescein on the $5^{\prime}$ end (Table 2). The amplified region shares $71 \%$ similarity with the orthologous gene in $B$. cinerea but includes 20 mismatches of base pairs, 17 of which are covered by the primer and probe sequences. The probe and primer sequences were used to query the GenBank databases using the Basic Local Alignment Search Tool (BLAST) in order to identify any similar sequences from other organisms that could lead to false positives.

Development of the exogenous positive internal control. To identify false negatives resulting from failed DNA extraction or inhibition of the PCR, an exogenous internal control was included in the analysis of all samples. The ToxB gene from Pyrenophora triticirepentis, causal agent of tan spot of wheat (Lamari and Strelkov 2010), was selected as the exogenous internal control because it is unlikely to be found in canola petals. The pSilent 1 plasmid (Nakayashiki et al. 2005) containing a 432-bp fragment of ToxB from P. tritici-repentis (Aboukhaddour et al. 2012) was used as the template for the design of the primers and hydrolysis probe. The ToxB-specific primers (ToxBF and ToxBR) and a probe (ToxBP) were designed using Primer 3 Express (Applied Biosystems). The ToxB-specific hydrolysis probe was labeled with NFQ-MGB on the $3^{\prime}$ end and with the reporter dye VIC on the $5^{\prime}$ end (Table 2).

For use as an internal control, every canola petal sample was spiked with $2 \times 10^{6}$ plasmids containing the ToxB gene prior to DNA isolation. Each sample was analyzed in two separate singleplex qPCR reactions, one with the ToxB primers and probe set and another with the $S$. sclerotiorum-specific primers and probe. To identify outliers and potential error, the standard deviation of the $\mathrm{C}_{\mathrm{q}}$ values obtained for the internal control in a set of samples was calculated. If the standard deviation was close to or less than 1.0 for a set of samples, the variation in the internal control and the risk of false negatives as a result of failed DNA isolation or PCR inhibition were regarded as low. Any samples that were outside of this range were discarded and DNA was isolated again.

qPCR analysis. The terminology used to describe the qPCR analysis will be as suggested in the Minimum Information for Publication of Quantitative Real-Time PCR Experiments guidelines (Bustin et al. 2009). All qPCR analyses were conducted in a ViiA7 RealTime PCR System (Life Technologies) using the Universal FastStart Master (Rox) mix (Roche, Indianapolis, IN) in a MicroAmp Fast Optical 96-well reaction plate (Applied Biosystems), which was sealed with MicroAmp optical adhesive film (Applied Biosystems,). Each qPCR was conducted in a total volume of $10 \mu \mathrm{l}$, including $0.1 \mu \mathrm{l}$ of each forward and reverse primer $(50 \mu \mathrm{M}$ SSBZF and $50 \mu \mathrm{M}$

Table 1. List of species used to test the specificity of primers and hydrolysis probes developed for the detection and quantification of Sclerotinia sclerotiorum and a ToxB internal control

\begin{tabular}{|c|c|c|c|c|}
\hline Species & Isolate & Origin $^{\mathbf{a}}$ & Source & Supplierb \\
\hline Sclerotinia sclerotiorum ${ }^{\mathrm{c}, \mathrm{d}}$ & UAMH 6321 & Devon, $\mathrm{AB}$ & Potted Garzania sp. & UAMCH \\
\hline S. sclerotiorum ${ }^{\mathrm{d}}$ & UAMH 4514 & Central Alberta & Rapeseed & UAMCH \\
\hline S. sclerotiorum ${ }^{\mathrm{d}}$ & UAMH 9192 & Maryland, United States & Bean stem & UAMCH \\
\hline S. sclerotiorum ${ }^{\mathrm{d}}$ & SSA-11 & Edmonton, $\mathrm{AB}$ & Canola petals & B. Ziesman, $\mathrm{U}$ of $\mathrm{A}$ \\
\hline S. sclerotiorum ${ }^{\mathrm{d}}$ & SSB-11 & Edmonton, $\mathrm{AB}$ & Canola petals & B. Ziesman, $\mathrm{U}$ of $\mathrm{A}$ \\
\hline S. sclerotiorum & SSC-11 & Edmonton, $\mathrm{AB}$ & Canola petals & B. Ziesman, $\mathrm{U}$ of $\mathrm{A}$ \\
\hline S. sclerotiorum ${ }^{\mathrm{d}}$ & SSD-11 & Edmonton, $\mathrm{AB}$ & Canola petals & B. Ziesman, $\mathrm{U}$ of $\mathrm{A}$ \\
\hline S. minor & CBS 207.25 & Unknown & Unknown & CBS \\
\hline S. trifoliorum & CBS 122377 & The Netherlands & Unknown & CBS \\
\hline Botrytis cinerea & DR12-5 & Unknown & Potato tuber tissue & R. J. Howard, AARD \\
\hline B. cinerea & $414 J V$ & Unknown & Alfalfa & R. J. Howard, AARD \\
\hline B. cinerea & DAOM 192631 & Winnipeg, Manitoba & Fragaria chiloensis & $\mathrm{CCFC}$ \\
\hline B. cinerea & DAOM 189076 & Charlottetown, PEI & Potato tubers & $\mathrm{CCFC}$ \\
\hline B. cinerea & DAOM 166439 & Beaverlodge, $\mathrm{AB}$ & Festuca rubra & $\mathrm{CCFC}$ \\
\hline B. cinerea & CGC5 & PEI & Winter wheat & CGC \\
\hline Botryotinia fuckeliana ${ }^{\mathrm{e}}$ & UAMH 16 & Unknown & Bean & UAMCH \\
\hline B. fuckeliana & UAMH 1784 & Beaverlodge, $\mathrm{AB}$ & $\begin{array}{l}\text { Indoor air exchange strip from Apis mellifera } \\
\text { equipment cleaning warehouse }\end{array}$ & UAMCH \\
\hline Rhizoctonia solani & $N / A^{f}$ & Unknown & Unknown & J.P. Tewari, U of A \\
\hline Rhizopus spp. & N/A & Unknown & Unknown & J.P. Tewari, U of A \\
\hline Trichoderma spp. & N/A & Unknown & Soil & J. P. Tewari, U of A \\
\hline Penicillium spp. & N/A & Edmonton, $\mathrm{AB}$ & Canola petals & B. Ziesman, $\mathrm{U}$ of A \\
\hline Aspergillus niger & N/A & Unknown & Unknown & J. P. Tewari, U of A \\
\hline Cladosporium spp. & N/A & Edmonton, $\mathrm{AB}$ & Canola petals & B. Ziesman, $\mathrm{U}$ of $\mathrm{A}$ \\
\hline Mucor spp. & N/A & Edmonton, $\mathrm{AB}$ & Canola petals & B. Ziesman, $\mathrm{U}$ of A \\
\hline Alternaria alternata & N/A & Unknown & Unknown & J. P. Tewari, U of A \\
\hline Fusarium graminearum & G-1 & Unknown & Unknown & A. Tekauz, Agri-Food \\
\hline Leptosphaeria maculans & N/A & Unknown & Unknown & J. P. Tewari, U of A \\
\hline Brassica napus & N/A & Edmonton, $\mathrm{AB}$ & N/A & B. Ziesman, $\mathrm{U}$ of A \\
\hline
\end{tabular}

a City, province in Canada, except for "Unknown" or where another country is named.

b UAMCH = University of Alberta Microfungus Collection and Herbarium; U of A = University of Alberta, Agri-Food = Agriculture and Agri-Food Canada, Winnipeg, MB, Canada; CBS = Centraalbureau Voor Schimmelcultures, Royal Netherlands Academy of Arts and Sciences, Uppsalalaan, The Netherlands; AARD = Alberta Agriculture and Rural Development, Brooks, AB, Canada; CCFC = Canadian Collection of Fungal Cultures, Ottawa, ON, Canada; and CGC = Canadian Grain Commission, Winnipeg, MB, Canada .

c S. sclerotiorum UAMH 6321 was originally designated as S. minor in the UAMCH but later identified as S. sclerotiorum.

d Amplicon obtained from the isolate sequenced to confirm identity of the PCR product.

e Teleomorph of Botrytis cinerea; species names are given as provided by the original supplier.

${ }^{\mathrm{f}} \mathrm{N} / \mathrm{A}=$ not available or not applicable (for B. napus). 
SSBZR, respectively), $0.03 \mu \mathrm{l}$ of the hydrolysis probe $(100 \mu \mathrm{M}$ SSBZP), $5 \mu l$ of the $2 \times$ master mix (Rox), $0.77 \mu l$ of moleculargrade water (Life Technologies), and $4 \mu$ l of the template DNA or negative control. For the quantification of the internal control, the reaction mixture was as above, except that $0.025 \mu \mathrm{l}$ of the $100 \mu \mathrm{M}$ ToxBP hydrolysis probe and $0.775 \mu$ lof molecular-grade water (Life Technologies) were added and the primers ToxBF and ToxBR were substituted for SSBZF and SSBZR. The reaction conditions included a hot start at $95^{\circ} \mathrm{C}$ for $10 \mathrm{~min}$, followed by 40 cycles of $95^{\circ} \mathrm{C}$ for $10 \mathrm{~s}$ and $60^{\circ} \mathrm{C}$ for $30 \mathrm{~s}$, as per the manufacturer's instructions for the master mix. Each of the primer and probe sets was analyzed separately and reactions were not multiplexed. Each sample was analyzed in triplicate for quantification of the SS1G_00263 target, while samples were analyzed in duplicate for assays of the internal control. If the standard deviation of the mean $\mathrm{C}_{\mathrm{q}}$ obtained for a set of triplicates of a given sample was $>0.5$, the sample was reanalyzed and, if an outlier was present, it was removed. Similarly, if the standard deviation of the mean $\mathrm{C}_{\mathrm{q}}$ obtained for duplicates of the ToxB internal control was $>0.5$, the sample was reextracted.

Specificity testing. The specificity of the SS1G_00263 primer and probe set was confirmed by separately testing $100 \mathrm{ng}$ of DNA from 13 fungal species and the canola host as templates in the qPCR analysis (Table 1). In addition, amplification of a total of eight isolates of $B$. cinerea and seven isolates of $S$. sclerotiorum was compared. No amplification of any product, or a $\mathrm{C}_{\mathrm{q}}$ value $>2$ cycles below that of the smallest standard, were considered to be indicative of no detection. The reproducibility of the standard curve was assessed by calculating the standard deviation at each point for four replications included in separate 96-well plates. Plasmids containing the ToxB insert were analyzed with the SS1G_00263-specific primer set to ensure that the SSBZF/SSBZR set did not amplify the internal control.

Sequencing of PCR products. Amplicons obtained with the SSBZF/SSBZR primer set were sequenced to confirm the identity of the product. Conventional PCR was used to increase the amount of amplicon obtained from pure mycelial DNA of six S. sclerotiorum isolates (UAMH 6321, UAMH 4514, UAMH 9192, SSA-11, SSB-11, and SSD-11) for sequencing purposes. The PCR analysis was carried out in a $25-\mu$ l reaction volume, which consisted of $15.4 \mu \mathrm{l}$ of molecular-grade water (Life Technologies), $2 \mu$ of 10× PCR buffer (no magnesium chloride; Invitrogen by Life Technologies), $1 \mu \mathrm{l}$ of $2.5 \mathrm{mM}$ each dNTP, $1 \mu \mathrm{l}$ of $50 \mathrm{mM} \mathrm{MgCl} 2,0.2 \mu \mathrm{l}$ each of $50 \mathrm{mM}$ SSBZF and SSBZR, $0.2 \mu \mathrm{l}$ of Platinum Taq DNA Polymerase (Invitrogen), and $5 \mu \mathrm{l}(100 \mathrm{ng}$ ) of template DNA. The reaction conditions were $94^{\circ} \mathrm{C}$ for $3 \mathrm{~min}$; followed by 40 cycles of $94^{\circ} \mathrm{C}$ for $30 \mathrm{~s}, 60^{\circ} \mathrm{C}$ for $20 \mathrm{~s}$, and $72^{\circ} \mathrm{C}$ for $5 \mathrm{~min}$; and ending with an incubation at $72^{\circ} \mathrm{C}$ for $5 \mathrm{~min}$ followed by a constant $4^{\circ} \mathrm{C}$. PCR products were resolved on a $2 \%$ agarose gel run at $90 \mathrm{~V}$ for $50 \mathrm{~min}$. The amplicon band was extracted using a Qiaquick Gel Extraction Kit (Qiagen) and sent to the Molecular Biology Service Unit, University of Alberta, Edmonton, AB, Canada for sequencing. Sequencing was conducted on a 3730 Genetic Analyzer (Applied Biosystems) with Sanger cycle sequencing using fluorescently labeled dye terminators and BigDye Terminator v1.1 chemistry.

Sensitivity testing. To test the limit of detection (LOD) of the assay, standard curves were generated with 1:10 serial dilutions of purified S. sclerotiorum DNA. All standard curves tested consisted of five serial dilutions ranging from $8.0 \mathrm{ng}$ to $8.0 \times 10^{-4} \mathrm{ng}$ or from $5.0 \mathrm{ng}$ to $5.0 \times 10^{-4} \mathrm{ng}$. Each standard was included in triplicate in the same 96-well plate as the samples being analyzed. The LOD was regarded as the lowest quantity of DNA that could be detected with confidence in all three of the triplicates. The efficiency and coefficient of determination $\left(R^{2}\right)$ of the standard curves were determined for each replication. The reproducibility of the standard curve was assessed by calculating the standard deviation at each point for four replications included in separate 96-well plates. A standard deviation of $<0.5$ for the average $\mathrm{Cq}$ values of the four replications was considered to indicate that the assay was reliable.

To determine whether inclusion of the internal control and the presence of Brassica napus DNA reduced the LOD for S. sclerotiorum, fungal DNA was quantified in the presence or absence of the
ToxB internal control and B. napus DNA. A 1:5 dilution series ranging from $4.0 \times 10^{1} \mathrm{ng}$ to $5.0 \times 10^{-4} \mathrm{ng}$ of $S$. sclerotiorum DNA was spiked with $2 \mu l$ of B. napus DNA and $2 \times 10^{5}$ copies of the plasmid containing the internal control. The $B$. napus DNA represented a 1:5 dilution of total genomic DNA extracted from a set of 20 canola petals that were not infected with $S$. sclerotiorum. The mean $\mathrm{C}_{\mathrm{q}}$ and standard deviation of the mean for each point in the dilution series were compared between the spiked and nonspiked samples.

Evaluation of canola petals. Total genomic DNA isolated from samples consisting of 20 canola petals each was diluted by a factor of 1:5 with nuclease-free water (Life Technologies) prior to $\mathrm{qPCR}$ analysis with the SS1G_00263- and ToxB-specific primers and probes. DNA was analyzed from samples collected at five sampling sites from each of 10 commercial canola fields at each of two sampling dates, as described above. Results are expressed on a perpetal basis by first accounting for the dilution, then dividing the estimate by 20 . The qPCR estimates were averaged over each field on each sampling date and the standard deviation of the mean was calculated for each field. Any sample from which no $S$. sclerotiorum DNA could be amplified or which was below the lowest standard outside the range of the standard curve was recorded as $0 \mathrm{ng}$ of S. sclerotiorum DNA per canola petal.

Assessment of the SsF and SsR primer set. Isolates of S. sclerotiorum collected from canola fields in central Alberta were subjected to qPCR analysis with the primers SsF (5' AGTCGAGGGACGGGTACTAA 3') and SsR (5' CTTGTCCTCATTGCCGTTT 3') developed by Yin et al. (2009). The primers were evaluated using Dynamite qPCR Mastermix (Molecular Biology Service Unit, University of Alberta, Edmonton) instead of the SYBR Premix Ex Taq (TaKaRa Biotechnology Co. Ltd., Dalian, China) used by Yin et al. (2009) but both of these master mixes rely on the intercalating dye SYBR Green as the basis of detection. The reaction conditions consisted of an initial heat denaturation at $95^{\circ} \mathrm{C}$ for $2 \mathrm{~min}$ followed by 40 cycles of $95^{\circ} \mathrm{C}$ for $15 \mathrm{~s}$ and $60^{\circ} \mathrm{C}$ for $60 \mathrm{~s}$, as recommended by the manufacturer. These differ slightly from the conditions used by Yin et al. (2009) but are optimized for the Dynamite qPCR Mastermix utilized in the current analysis. qPCR assays were conducted in a Step One Plus Real-Time PCR System (Applied Biosystems) in a 10- $\mu 1$ total reaction volume containing $5 \mu$ l of Dynamite qPCR Mastermix, $0.8 \mu l$ of molecular-grade water, $0.1 \mu \mathrm{l}$ each of $50 \mathrm{mM} \mathrm{SsF}$ and SsR, and $4 \mu \mathrm{l}$ of template DNA solution. After the reaction was complete, a melting-point analysis was conducted to confirm the presence of a single amplification product that had a melting temperature $\left(\mathrm{T}_{\mathrm{M}}\right)$ consistent with the predicted $\mathrm{T}_{\mathrm{M}}$ of $84^{\circ} \mathrm{C}$. The specificity of the $\mathrm{SsF}$ and $\mathrm{SsR}$ primer set also was evaluated as described above for the other primer and probe sets.

\section{Results}

Amplicon generated with SSBZF/SSBZR. The amplicons generated from six isolates of $S$. sclerotiorum with the SSBZF/SSBZR primer set targeting the gene SS1G_00263 were sequenced and

Table 2. Primers and hydrolysis probes for detection and quantification of Sclerotinia sclerotiorum and a ToxB internal control ${ }^{\mathrm{a}}$

\begin{tabular}{llc}
\hline $\begin{array}{l}\text { Primer or } \\
\text { probe name }\end{array}$ & \multicolumn{1}{c}{ Sequence } & Size (bp) \\
\hline SSBZF & 5'-GCTCCAGCAGCCATGGAA-3' & 18 \\
SSBZR & 5'-TGTTGAAGCAGTTGACGAGGTAGT-3' & 24 \\
SSBZP & 5'-CAGCGCCTCAAGC-3' & 13 \\
ToxBF & 5'-CCATGCTACTTGCTGTGGCTAT-3' & 22 \\
ToxBR & 5'-CGCAGTTGGCCGAAACA-3' & 17 \\
ToxBP & 5'-CTCCCTGCTGCCCC-3' & 13 \\
\hline
\end{tabular}

a Primer set SSBZF/SSBZR amplifies a 70-bp fragment of the gene SSIG 00263 in S. sclerotiorum and was used in conjunction with SSBZP in a hydrolysis probe-based assay to quantify $S$. sclerotiorum DNA. The primer set ToxBF/ToxBR amplifies a 70-bp fragment of the ToxB gene from Pyrenophora tritici-repentis and was used in conjunction with ToxBP to quantify the exogenous internal control in a hydrolysis probe-based assay. 
confirmed to be of the expected 70-bp size. Moreover, the sequences were identical to each other, and a query of the GenBank database using BLASTN revealed $100 \%$ identity with accession number XM_001598127.1 from S. sclerotiorum (e-value = 3e-31).

Specificity testing. Although the SS1G_00263-specific primers consistently amplified a 70-bp product from DNA of each of the S. sclerotiorum isolates evaluated, they did not generate an amplicon from any of the other 13 species tested, including the closely related Botrytis cinerea, S. trifoliorum, or S. minor (Table 3). Similarly, no amplicon was obtained from DNA of the host canola plant. Specificity testing with the ToxB-specific primers did not yield an amplicon from $S$. sclerotiorum or any of the nontarget organisms tested.

Sensitivity testing. The lowest reliable LOD was $8.0 \times 10^{-4} \mathrm{ng}$ of S. sclerotiorum DNA. Although the assay could detect quantities of $S$. sclerotiorum DNA as small as $5.0 \times 10^{-4} \mathrm{ng}$, such detection could not be accomplished with a standard deviation of the mean $\mathrm{C}_{\mathrm{q}}<0.5$. As such, the lowest point of the standard curve was set to $8.0 \times 10^{-4}$ ng of DNA. To compare replicates of the standard curve, the $\mathrm{C}_{\mathrm{q}}$ values were averaged for a set of comparisons and the standard deviation of the mean for each point on the curve was calculated. An average standard deviation of 0.19 was obtained for the mean $\mathrm{C}_{\mathrm{q}}$ over all five points on the curve, among four replicates of the standard curve in separate 96-well plates; none of the points had a standard deviation $>0.5$ (Fig. 1). For the four replicates of the standard curve generated in separate 96-well plates, the PCR efficiencies ranged from 88.90 to 90.25 and the $R^{2}$ values ranged from 0.9928 to 0.9999 .

Curves generated with the SS1G_00263-specific primers in the presence or absence of the internal control and Brassica napus DNA were compared to identify any potential reduction in the quantification of $S$. sclerotiorum DNA. The $\mathrm{C}_{\mathrm{q}}$ values were averaged for each dilution point in the two dilution series and the standard deviation of the $\mathrm{C}_{\mathrm{q}}$ values for the replicates was calculated. Each point on the standard curves was compared individually and no single point had a standard deviation of the mean $\mathrm{C}_{\mathrm{q}}>0.54$ (Fig. 2).

Quantification of $S$. sclerotiorum in canola petals. Total genomic DNA extracted from 20 petals from each of five sampling sites in each of 10 commercial canola fields on two different sampling dates (100 DNA samples in total) was used as a template for qPCR analysis. The petal infestation estimates for individual sampling sites

Table 3. Results of specificity testing with the $\mathrm{SsF} / \mathrm{SsR}$ primer set (Yin et al. 2009) and SSBZF/SSBZR primer set ${ }^{\mathrm{a}}$

\begin{tabular}{|c|c|c|}
\hline Fungal species & $\begin{array}{c}\mathrm{C}_{\mathbf{q}} \text { value } \\
(\mathrm{SsF} / \mathrm{SsR})\end{array}$ & $\begin{array}{c}\mathrm{C}_{\mathrm{q}} \text { value } \\
(\mathrm{SSBZF} / \mathrm{SSBZR})\end{array}$ \\
\hline$\overline{\text { Sclerotinia trifoliorum }}$ & 27.673 & ND \\
\hline S. minor & ND & ND \\
\hline $\begin{array}{l}\text { Botryotinia fuckeliana UAMH } \\
1784\end{array}$ & 33.219 & ND \\
\hline B. fuckeliana UAMH 16 & 35.017 & ND \\
\hline Botrytis cinerea DR12-5 & 34.954 & ND \\
\hline B. cinerea DAOM 192631 & 34.099 & ND \\
\hline B. cinerea DAOM 166439 & 35.017 & ND \\
\hline Rhizopus spp. & 34.285 & ND \\
\hline Trichoderma spp. & 30.617 & ND \\
\hline Rhizoctonia spp. & 35.330 & ND \\
\hline Penicillium spp. & 31.550 & ND \\
\hline Aspergillus niger & ND & ND \\
\hline Fusarium graminearum & 30.037 & ND \\
\hline Cladosporium spp. & ND & ND \\
\hline Mucor spp. & ND & ND \\
\hline Alternaria alternata & ND & ND \\
\hline Leptosphaeria maculans & ND & ND \\
\hline $8.0 \times 10^{-4} \mathrm{ng}$ of $S$. sclerotiorum & 33.068 & 33.662 \\
\hline
\end{tabular}

DNA

${ }^{a}$ The quantification cycle $\left(\mathrm{C}_{\mathrm{q}}\right)$ value indicates the cycle number at which fluorescence from amplification of a product exceeds background fluorescence. $\mathrm{ND}=$ no detection; indicates that there was no amplification of the fungal DNA or that the $\mathrm{C}_{\mathrm{q}}$ value was at least three cycles greater than the lowest standard ( $8.0 \times 10^{-4} \mathrm{ng}$ of $S$. sclerotiorum DNA). ranged from 0 ng to $3.3 \times 10^{-1} \mathrm{ng}$ of $S$. sclerotiorum DNA per petal. The amount of $S$. sclerotiorum DNA in each of the five sampling sites per field was averaged to give a single petal infestation estimate for each field on each sampling date (Fig. 3). On the first sampling date, when the canola was at 20 to $30 \%$ bloom, average infestation in the 10 fields ranged from a mean ( \pm standard deviation) of $6.0 \times 10^{-3} \mathrm{ng}$ $\pm 7.0 \times 10^{-3} \mathrm{ng}$ to $3.4 \times 10^{-2} \mathrm{ng} \pm 2.8 \times 10^{-2} \mathrm{ng}$ of $S$. sclerotiorum DNA per petal $\left(\mathrm{C}_{\mathrm{q}}\right.$ values $=30.5$ to 36.1$)$. On the second sampling date, at 40 to $50 \%$ bloom, average infestation in the 10 fields ranged from a mean ( \pm standard deviation) of $1.0 \times 10^{-3} \mathrm{ng} \pm 1.0 \times 10^{-3} \mathrm{ng}$ to $8.0 \times 10^{-2} \mathrm{ng} \pm 1.4 \times 10^{-1} \mathrm{ng}$ of $S$. sclerotiorum DNA per petal $\left(\mathrm{C}_{\mathrm{q}}\right.$ values $=28.9$ to 36.1$)$.

In addition to the analysis with the SS1G_00263-specific primer and probe set, all samples were analyzed with the ToxB (internal control)-specific primer and probe set in separate, singleplex qPCR assays. The mean and standard deviation of the mean $\mathrm{C}_{\mathrm{q}}$ value for duplicates was calculated for early bloom and late bloom sample sets to get an estimate of the amount of variation. At 20 to $30 \%$ bloom, the overall mean $\mathrm{C}_{\mathrm{q}}$ ( \pm standard deviation) was $29.6 \pm 1.08$ and, at 40 to $50 \%$ bloom, the overall mean $\mathrm{C}_{\mathrm{q}}( \pm$ standard deviation) was $27.6 \pm 0.70$.

Assessment of the SsF and SsR primers. The primers SsF and SsR (Yin et al. 2009) were evaluated to determine their suitability for quantifying $S$. sclerotiorum DNA in canola petals under Canadian conditions. The primers amplified a product of approximately $225 \mathrm{bp}$ from all isolates of $S$. sclerotiorum and did not amplify DNA of S. minor, Aspergillus niger, Cladosporium spp., Mucor spp., Alternaria alternata, or Leptosphaeria maculans (Table 3). However, the

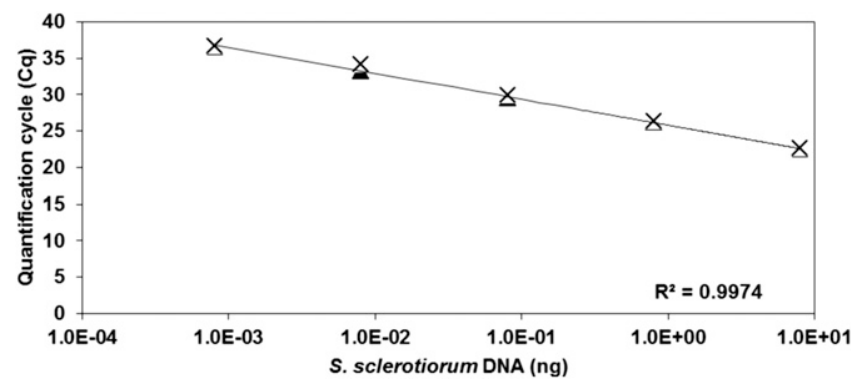

Fig. 1. Standard curves obtained with DNA extracted from Sclerotinia sclerotiorum and subjected to quantitative polymerase chain reaction (PCR) analysis with the primer set SSBZF/SSBZR and hydrolysis probe SSBZP. Four replicates of the standard curve were run in separate 96-well plates. The standards were prepared from a serial dilution of $8.0 \mathrm{ng}$ to $8.0 \times 10^{-4} \mathrm{ng}$ of $S$. sclerotiorum DNA. The four replications are denoted by different symbols, which may not be clearly visible because the curves overlap. The PCR efficiency $(E)$ of the four standard curves ranged from 88.9 to 90.25 and the coefficient of determination $\left(R^{2}\right)$ values for the individual standard curves ranged from 0.9928 to 0.9999 (average: 0.996).

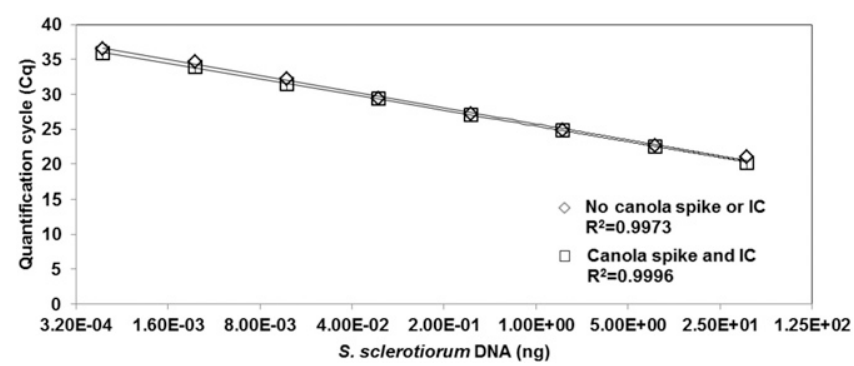

Fig. 2. Quantification of Sclerotinia sclerotiorum DNA in the presence or absence of canola (Brassica napus) DNA and a ToxB-internal control. The fungal DNA was serially diluted by a factor of $1: 5$ from $4.0 \times 10^{1} \mathrm{ng}$ to $5.0 \times 10^{-4} \mathrm{ng}$, and analyzed by quantitative polymerase chain reaction with the primer set SSBZF/SSBZR and hydrolysis probe SSBZP. Samples were analyzed in the absence (diamonds) or presence of a ToxB-internal control (IC) and Brassica napus DNA ('Canola spike') (squares). The standard deviation of the mean $\mathrm{C}_{\mathrm{q}}$ for any point along the curve was not $>0.54$, suggesting that the presence of host DNA or the IC did not affect the quantification of $S$. sclerotiorum DNA. The standard deviation at each point of the standard curve is reflected by the error bars. 
primers were found to amplify products from DNA of $S$. trifoliorum, as well as from all isolates tested of Botrytis cinerea, Botryotinia fuckeliana, Rhizopus spp., Trichoderma spp., Rhizoctonia solani, Penicillium spp., and Fusarium graminearum. The amplicons obtained from Botrytis cinerea, S. trifoliorum, and Trichoderma spp. all had temperature peaks between 84 and $85^{\circ} \mathrm{C}$, which was within the range expected for the product from $S$. sclerotiorum. For the products amplified from DNA of Botryotinia fuckeliana, Rhizopus spp., $R$. solani, Penicillium spp., and $F$. graminearum, the melting-curve analysis revealed the presence of multiple temperature peaks associated with nonspecific amplification. The sensitivity of the $\mathrm{SsF} / \mathrm{SsR}$ primer set was similar to that of the SSBZF/SSBFR primers, with a consistent LOD of $8.0 \times 10^{-4} \mathrm{ng}$ of DNA.

\section{Discussion}

This study focused on the development of a qPCR-based assay for the quantification of $S$. sclerotiorum DNA in canola petals to enable rapid and accurate estimates of infestation levels. The assay targets a 70-bp region of a single-copy gene encoding the hypothetical secreted protein ssv263 (Liang et al. 2013). Although the target region of the gene shares $71 \%$ similarity with an ortholog in Botrytis cinerea, specificity testing indicated that there was no amplification of DNA from any of six B. cinerea isolates tested. The qPCR assay also did not amplify DNA from any of the 13 other species evaluated in this study, including S. minor, S. trifoliorum, and the host plant, Brassica napus. These results indicate that the assay is highly specific for $S$. sclerotiorum and can be used to estimate pathogen biomass in canola petals.

The sensitivity tests revealed a consistent LOD of $8.0 \times 10^{-4} \mathrm{ng}$ of S. sclerotiorum DNA. Rogers et al. (2008) reported that an ascospore of $S$. sclerotiorum is equivalent to about $3.5 \times 10^{-4} \mathrm{ng}$ of DNA, suggesting an LOD of 2.3 ascospores/petal for the current assay. When adjusted to account for the dilution of DNA from canola petals during extraction and analysis, the LOD would correspond to $1.5 \times 10^{-3} \mathrm{ng}$ of $S$. sclerotiorum DNA or 4.3 ascospores/petal. An issue with the use of ascospores as the basis for a standard curve to quantify petal infestation, however, is that this approach will not reflect increases in pathogen biomass associated with spore germination. Ascospores have been shown to begin germination as early as $3 \mathrm{~h}$ after release from the apothecium under favorable environmental conditions (Willetts and Wong 1980). Therefore, it is likely that any assay examining the amount of $S$. sclerotiorum DNA on canola petals is measuring DNA from the ascospores as well as from hyphae developing from germinated spores. As such, quantification of $S$. sclerotiorum on petals is more meaningful and accurate when expressed as the total amount of pathogen DNA. The specificity of the assay was not affected by the presence of B. napus DNA or of an internal control in the samples. These are important considerations if the assay is to be used to measure infestation of petals collected in the field.

Yin et al. (2009) developed a qPCR assay to measure S. sclerotiorum DNA in canola petals using intercalating dye (SYBR Green) detection technology that detected pathogen DNA at 0.0252 to $0.111 \mathrm{ng} / \mathrm{mg}$ of canola petal tissue. Evaluation of the primers developed by Yin et al. (2009) on DNA extracted from Canadian isolates of $S$. sclerotiorum and other fungal species, using a different master mix but the same dye detection technology, indicated sensitivity similar to that of the assay described in this report. However, the specificity of the primers seemed considerably lower and amplicons were obtained from various nontarget species, including $S$. trifoliorum, Botrytis cinerea, F. graminearum, Rhizopus spp., and Penicillium spp. In their original report, Yin et al. (2009) found no amplification of DNA other than from $S$. sclerotiorum but only evaluated one isolate of B. cinerea (Botryotinia fuckeliana) and did not test $S$. minor, $S$. trifoliorum, or Rhizopus spp. They did test $R$. solani, Penicillium spp., and $F$. graminearum but did not detect any product from the isolates evaluated. This lower specificity represents a challenge for application of the earlier protocol (Yin et al. 2009) in the analysis of field samples and, hence, for its use as the basis for a Sclerotinia stem rot risk assessment system. Although it may be possible to identify nonspecific amplification products based on a melting-curve analysis, this would complicate the procedure and introduce the possibility of additional errors. Moreover, the quantification of field samples containing a range of different fungal species in addition to $S$. sclerotiorum may be difficult. The similar sensitivity but increased specificity of the assay developed in this study with the primers SSBZF and SSBZR and probe SSBZP may reflect the use of a hydrolysis probe instead of an intercalating dye. An intercalating dye, such as SYBR green, binds to any double-stranded DNA and releases a fluorescent signal (Ririe et al. 1997). This potentially can result in fluorescent amplification of nontarget double-stranded DNA that must be further differentiated through melting-curve analysis (Smith and Osborn 2009). The use of a hydrolysis probe ensures that a fluorescent signal is produced only when there is an exact match between the probe and the target (Smith and Osborn 2009). This increased level of specificity reduces the likelihood of false positives when analyzing diverse field samples, without compromising sensitivity. As a result, the newly developed qPCR assay may represent a more reliable method to quantify $S$. sclerotiorum DNA in canola petals.

When the hydrolysis probe-based qPCR assay was used to quantify $S$. sclerotiorum in field-collected canola petals, considerable variation was observed in the amount of petal infestation in different fields and at different crop stages. Environmental conditions in 2012 were conducive to stem rot development in the sampled fields. In 5 of 10 fields, infestation levels were highest at 40 to $50 \%$ bloom whereas, in the remaining 5 fields, the infestation levels were highest at 20 to $30 \%$ bloom. This is consistent with the findings of Turkington and Morrall (1993), who reported changes in petal infestation from early to late bloom and at different locations when culturing petals on growth medium. Similarly, using qPCR analysis, Almquist and Wallenhammar (2015) also observed differences in S. sclerotiorum incidence at different stages of flowering. The evaluation of petals by qPCR analysis over the flowering period could provide an indication of when inoculum levels are highest and, thus, when the crop may benefit most from fungicide application. The variation in the amount of S. sclerotiorum DNA between locations may reflect differences in inoculum level or in the timing of ascospore release, crop seeding date and growth stage, canopy density, or microclimatic conditions. It also indicates the importance of assessing petal infestation and risk potential for a particular field as opposed to an assessment of risk based on regional conditions. The inclusion of an internal control helped to identify outliers resulting from possible human error or other artifacts, such as inhibition of the PCR, thereby improving the accuracy of qPCR-based estimates of petal infestation.

The qPCR assay described in this study may serve as the basis for a risk assessment system, as well as representing a useful tool for the study of the epidemiology of Sclerotinia stem rot of canola. It can quantify the level of petal infestation, a key stage in the Sclerotinia

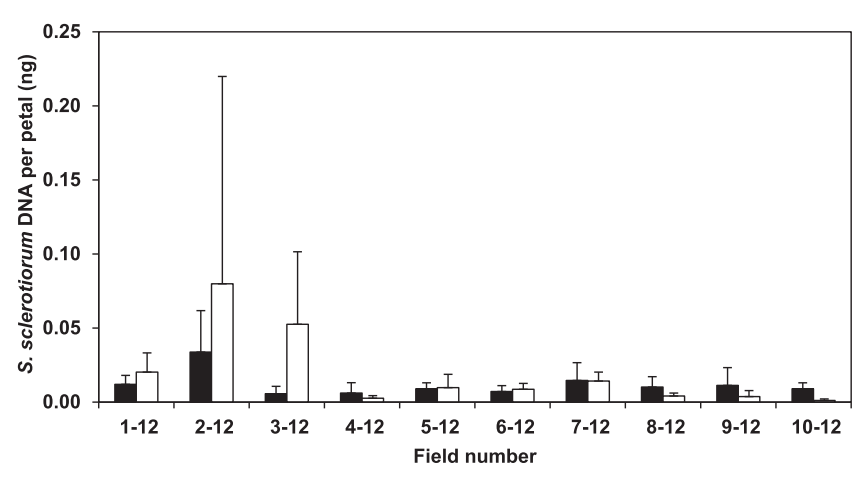

Fig. 3. Quantification of Sclerotinia sclerotiorum DNA on canola petals collected from commercial fields in the Edmonton, $A B$, Canada region, as determined by quantitative polymerase chain reaction analysis with the primer set SSBZF/SSBZR and hydrolysis probe SSBZP. Five sites per field in each of 10 fields were sampled at 20 to $30 \%$ bloom (black bars) and 40 to $50 \%$ bloom (white bars). Error bars represent the standard deviation of the mean for each field and reflect the amount of variation across the five sampling sites within each field. 
stem rot disease cycle, thereby providing a measure of disease risk when timely fungicide application decisions need to be made. To further investigate the possibility of developing a forecasting system based on this technology, the relationship between the petal infestation estimates and final stem rot incidence must be determined. The strength of the relationship between petal infestation as assessed through qPCR analysis and final disease incidence can be investigated with the use of regression analysis. It is also important to emphasize that a forecasting system based on qPCR quantification of petal infestation should be linked to environmental conditions as well as cropping history, seeding date, and crop canopy conditions, which may influence Sclerotinia stem rot development and the need to spray a fungicide. Validation as a predictive tool under field conditions is the focus of a follow-up study.

\section{Acknowledgments}

This work would not have been possible without the generous support of the Alberta Crop Industry Development Fund, the Alberta Canola Producers Commission, the Western Grains Research Foundation, and Agriculture and Agri-Food Canada and the Canola Council of Canada via the Growing Forward program. We thank R. J. Howard (Alberta Agriculture and Rural Development, Brooks, $\mathrm{AB}$, Canada) for providing isolates of Botrytis cinerea; $\mathrm{R}$. Aboukhaddour (University of Alberta) for providing the plasmid used to develop the internal control; I. Strelkov, D. Rennie, T. Locke, and T. Cao (University of Alberta) for technical assistance; and E. deMilliano and R. Adams (Crop Production Systems, Ft. Saskatchewan, AB, Canada) and several cooperating farmers for assisting with petal collection and including a fungicide-free check strip in their crops.

\section{Literature Cited}

Abawi, G. S., and Grogan, R. G. 1979. Epidemiology of diseases caused by Sclerotinia species. Phytopathology 69:899-904.

Aboukhaddour, R., Kim, Y. M., and Strelkov, S. E. 2012. RNA-mediated gene silencing of ToxB in Pyrenophora tritici-repentis. Mol. Plant Pathol. 13:318326.

Almquist, C., and Wallenhammar, A.-C. 2015. Monitoring of plant and airborne inoculum of Sclerotinia sclerotiorum in spring oilseed rape using real-time PCR. Plant Pathol. 64:109-118.

Bardin, S. D., and Huang, H. C. 2001. Research on biology and control of Sclerotinia diseases in Canada. Can. J. Plant Pathol. 23:88-98.

Bolton, M. D., Bart, T., Thomma, P. H. J., and Nelson, B. D. 2006. Sclerotinia sclerotiorum (Lib.) de Bary: Biology and molecular traits of a cosmopolitan pathogen. Mol. Plant Pathol. 7:1-16.

Bustin, S. A., Benes, V., Garson, J. A., Hellemans, J., Huggett, J., Kubista, M., Mueller, R., Nolan, T., Pfaffl, M. W., Shipley, G. L., Vandesompele, J., and Wittwer, C. T. 2009. The MIQE guidelines: Minimum information for publication of quantitative real-time PCR experiments. Clin. Chem. 55:611622.

Canola Council of Canada. 2014. Canola encyclopedia: Sclerotinia stem rot. Online publication. Canola Council of Canada, Winnipeg, Manitoba, Canada. http://www.canolacouncil.org/canola-encyclopedia/diseases/sclerotiniastem-rot/\#variety-selection-and-genetic-resistancetolerance

Carpenter, M. A., Frampton, C., and Stewart, A. 1999. Genetic variation in New Zealand populations of the plant pathogen Sclerotinia sclerotiorum. N. Z. J. Crop Hortic. Sci. 27:13-21.

Clarkson, J. P., Staverley, J., Phelps, K., Young, C. S., and Whipps, J. M. 2003. Ascospore release and survival in Sclerotinia sclerotiorum. Mycol. Res. 107: 213-222.

del Río, L. E., Bradley, C. A., Hensen, R. A., Endres, G. J., Hanson, B. K., McKay, K., Halvorson, M., Porter, P. M., Le Gare, D. G., and Lamey, H. A. 2007. Impact of Sclerotinia stem rot on yield of canola. Plant Dis. 91:191-194.

Freeman, J., Ward, E., Calderon, C., and McCartney, A. 2002. A polymerase chain reaction (PCR) assay for the detection of inoculum of Sclerotinia sclerotiorum. Eur. J. Plant Pathol. 108:877-886.

Gugel, R. K., and Morrall, R. A. A. 1986. Inoculum disease relationships in Sclerotinia stem rot of rapeseed in Saskatchewan. Can. J. Plant Pathol. 8:89-96.

Harper, F. R., and Berkenkamp, B. 1975. Revised growth-stage key for Brassica campestris and B. napus. Can. J. Plant Sci. 55:657-658.

Jamaux, I., Gelie, B., and Lamarque, C. 1995. Early stages of infection of rapeseed petals and leaves by Sclerotinia sclerotiorum revealed by scanning electron microscopy. Plant Pathol. 44:22-30.
Koch, S., Dunker, S., Kleinhenz, B., Röhrig, M., and Von Tiedemann, A. 2007. A crop loss-related forecasting model for Sclerotinia stem rot in winter oilseed rape. Phytopathology 97:1186-1194.

Kora, C., McDonald, M. R., and Boland, G. J. 2005. Epidemiology of Sclerotinia rot of carrot caused by Sclerotinia sclerotiorum. Can. J. Plant Pathol. 27:245-258.

Lamari, L., and Strelkov, S. E. 2010. The wheat/Pyrenophora tritici-repentis interaction: Progress towards an understanding of tan spot disease. Can. J. Plant Pathol. 32:4-10.

Lancashire, P. D., Bleiholder, H., Langelüddecke, P., Stauss, R., Van Den Boom, T., Weber, E., and Witzen-Berger, A. 1991. A uniform decimal code for growth stages of crops and weeds. Ann. Appl. Biol. 119:561-601.

Liang, Y., Yajima, W., Davis, M. R., Kav, N. N. V., and Strelkov, S. E. 2013. Disruption of a gene encoding a hypothetical secreted protein from Sclerotinia sclerotiorum reduces its virulence on canola (Brassica napus). Can. J. Plant Pathol. 35:46-55.

Ma, Z., Luo, Y., and Michailides, T. J. 2003. Nested PCR assays for detection of Monilinia fructicola in stone fruit orchards and Botryosphaeria dothidea from pistachios in California. J. Phytopathol. 151:312-322.

McLaren, D. L., Conner, R. L., Platford, R. G., Lamb, J. L., Lamey, H. A., and Kutcher, H. R. 2004. Predicting diseases caused by Sclerotinia sclerotiorum on canola and bean-A western Canadian perspective. Can. J. Plant Pathol. 26:489-497.

Morrall, R. A. A., and Dueck, J. 1982. Epidemiology of Sclerotinia stem rot of rapeseed in Saskatchewan. Can. J. Plant Pathol. 4:161-168.

Morrall, R. A. A., and Thomson, J. R. 1991. Petal Test Manual for Sclerotinia in Canola. University of Saskatchewan, Saskatoon, Saskatchewan, Canada.

Nakayashiki, H., Hanada, S., Nguyen, B. Q., Kadotani, N., Tosa, Y., and Mayama S. 2005. RNA silencing as a tool for exploring gene function in ascomycete fungi. Fungal Genet. Biol. 42:275-283.

Parker, M. L., McDonald, M. R., and Boland, G. J. 2014. Evaluation of air sampling and detection methods to quantify airborne ascospores of Sclerotinia sclerotiorum. Plant Dis. 98:32-42.

Pratt, S. 2012. Sclerotinia resistant canola provides new option. Online publication. West. Prod. July 2012. http://www.producer.com/2012/07/sclerotinia-resistantcanola-provides-new-option/

Purdy, L. H. 1979. Sclerotinia sclerotiorum history, diseases and symptomology, host range, geographic distribution and impact. Phytopathology 69:875-880.

Ririe, K. M., Rasmussen, R. P., and Wittwer, C. T. 1997. Product differentiation by analysis of DNA melting curves during the Polymerase Chain Reaction. Anal. Biochem. 245:154-160.

Rogers, S. L., Atkins, S. D., and West, J. S. 2009. Detection and quantification of airborne inoculum of Sclerotinia sclerotiorum using quantitative PCR. Plant Pathol. 58:324-331

Schwartz, H. F., and Steadman, J. R. 1978. Factors affecting sclerotium populations of, and apothecium production by, Sclerotinia sclerotiorum. Phytopathology 68: 383-388.

Shah, P., Atwoood, J. A., III, Orland, R., Mubarek, H. E., Podila, G. K., and Davis, M. R. 2009. Comparative proteomic analysis of Botrytis cinerea secretome. J. Proteome Res. 8:1123-1130.

Sirjusingh, C., and Kohn, L. M. 2001. Characterization of microsatellites in the fungal plant pathogen Sclerotinia sclerotiorum. Mol. Ecol. Notes 1:267-269.

Smith, C. J., and Osborn, A. M. 2009. Advantage and limitations of quantitative PCR (Q-PCR)-based approaches in microbial ecology. FEMS Microbiol. Ecol. 67:6-20.

Turkington, T. K., Kutcher, H. R., McLaren, D., and Rashid, K. Y. 2011. Managing Sclerotinia in oilseed and pulse crops. Prairie Soils Crops 4:105-113.

Turkington, T. K., and Morrall, R. A. A. 1993. Use of petal infestation to forecast Sclerotinia stem rot of canola: The influence of inoculum variation over the flowering period and canopy density. Phytopathology 83:682-689.

Turkington, T. K., Morrall, R. A. A., and Gugel, R. K. 1991. Use of petal infestation to forecast Sclerotinia stem rot of canola: Evaluation of early bloom sampling, 1985-90. Can. J. Plant Pathol. 13:50-59.

Weber, E., and Bleiholder, H. 1990. Erläuterungen zu den BBCH-Dezimal—Codes für die Entwicklungsstadien von Mais, Raps, Faba-Bohne, Sonnenblume und Erbse-mit Abbildungen. Gesunde Pflanzen 42:308-321.

Willetts, H. J., and Wong, J. A.-L. 1980. The biology of Sclerotinia sclerotiorum, $S$. trifoliorum, and S. minor with emphasis on specific nomenclature. Bot. Rev. 46:101-165.

Wu, B. M., and Subbarao, K. V. 2008. Effects of soil temperature, soil moisture and burial depths on carpogenic germination of Sclerotinia sclerotiorum and S. minor. Phytopathology 98:1144-1152.

Yin, Y., Ding, L., Lui, X., Yang, J., and Ma, Z. 2009. Detection of Sclerotinia sclerotiorum in planta by a real-time PCR assay. J. Phytopathol. 157:465-469.

Young, C. S., and Werner, C. P. 2012. Infection routes for Sclerotinia sclerotiorum in apetalous and fully petalled winter oilseed rape. Plant Pathol. 61:730-738. 